\title{
RELACIONES DE PRODUCCIÓN Y CONFLICTO CAPITAL-TRABAJO EN LA ECONOMÍA POLÍTICA
}

\author{
RELATIONS OF PRODUCTION AND CAPITAL-LABOR CONFLICT IN \\ THE POLITICAL ECONOMY
}

Fahd Boundi

Universidad Complutense, Madrid. España/Spain

fahdbc@gmail.com

Recibido/Received: 30/02/2014

Modificado/Modified: 25/04/2014

Aceptado/Accepted: 20/07/2014

\section{RESUMEN}

El presente trabajo versa sobre la interpretación que realizan diferentes escuelas de la economía sobre las relaciones de producción y el conflicto capital-trabajo, con el objeto de conectarlas con el estudio social y político de la realidad económica. Para ello, se realiza una literatura comparada, comenzando con los aportes de Marx, sobre las relaciones de clase, la ley del valor, la formación de precios, la ganancia y la competencia, así como su conexión con la teoría de Ricardo. De este modo, indagaremos en la influencia que ha ejercido la teoría marxiana en el enfoque neoclásico, el pensamiento de Schumpeter y el análisis de Kalecki.

\section{PALABRAS CLAVE}

Relaciones de clase, Estado capitalista, fuerza de trabajo, valor, precio.

\section{SUMARIO}

1. Introducción. 2. Valor, trabajo abstracto y plusvalor: Marx, Ricardo y la crítica neoclásica. 3. Relaciones de producción y conflicto capital-trabajo después de Marx: Schumpeter y Kalecki. 3.1. Schumpeter: competencia real y destrucción creativa. 3.2. Kalecki: tasa de ganancia, conflicto capitaltrabajo y ciclo político. 4. Conclusiones. Bibliografia.

\begin{abstract}
This paper focuses on the interpretation made by different schools of economics about the relations of production and the capital-labor conflict, in order to connect with the social and political study of economic reality. For this, we will perform a comparative literature, beginning with Marx's contributions about class relations, law of value, price formation and profit, and its connection with Ricardo's theory. So, we will examine the influence exercised by the Marxian theory in neoclassical approach, Schumpeter thought and Kalecki analysis.
\end{abstract}

\section{KEYWORDS}

Class relations, Capitalist State, labor power, value, price.

\section{CONTENTS}

1. Introduction. 2. Value, abstract labour and surplus value: Marx, Ricardo and neoclassical criticism.

3. Relations of production and capital-labor conflict after Marx: Schumpeter and Kalecki. 3.1. Schumpeter: real competition and creative destruction. 3.2. Kalecki: profit rate, capital-labor conflict and political cycle. 4. Conclusions. References 


\section{INTRODUCCIÓN}

El paso del feudalismo al modo capitalista de producción en Europa Occidental supuso una vertiginosa transformación de las relaciones de producción $\mathrm{y}$, en consecuencia, de las relaciones de clase; la producción y circulación de mercancías construyó "la relación de producción básica en la que determinados productores de mercancías se vinculan directamente, estableciéndose de este modo para cada uno de ellos la conexión entre su actividad y la de todos los miembros de la sociedad" (Rubin, 1974:64). En vista de ello, podemos afirmar que "el rasgo más importante del capitalismo es la producción de mercancías, es decir la producción no para uso directo sino para el mercado" (Bhaduri, 1990:16). Asimismo, la producción capitalista de mercancías es un sistema de producción de mercancías por medio de mercancías, pues la "riqueza de las sociedades en que impera el régimen capitalista de producción se nos parece como un "inmenso arsenal de mercancías" y la mercancía como su forma elemental" (Marx, 2006:3). Mas, por otra parte, la producción de mercancías es una condición necesaria, pero no siempre suficiente, pues, como subraya Ernst Mandel, civilizaciones como la antigua Grecia o el Imperio Árabe desarrollaron la producción de mercancías en pequeña escala, empero, la "producción de mercancías en estos modos precapitalistas de producción está entrelazada y en última instancia subordinada (en primer lugar la producción agrícola) de una naturaleza claramente no capitalista" (Mandel, 1985:12). Ahora bien, aquello en forma alguna implica que las sociedades donde la producción en pequeña escala es predominante, "las leyes que rigen el intercambio de mercancías y la circulación de dinero no influyan fuertemente sobre la dinámica económica" (Mandel, 1985:13).

Por tal razón, Karl Marx hubo de investigar en aquello que definieron sus predecesores como la acumulación previa o acumulación originaria; el filósofo de Tréveris se refirió a la acumulación originaria como expropiación originaria, pues ésta se concibió como "una serie de procesos históricos que acabaron destruyendo la unidad originaria que existía entre el hombre trabajador y sus medios de trabajo" (Marx, 1978:212). En efecto, el punto cardinal del modo de producción capitalista es la separación entre los productores y sus medios de producción.

En consecuencia, el divorcio entre el trabajo y los medios de producción es el hecho objetivo de carácter histórico que constituye el trabajo asalariado como el modo social predominante en el capitalismo y, por ende, configura la estructura de clases (Marx, 1978, 2006a, 2006b, 2006c; Mandel, 1985; Rubin, 1974; Bhaduri, 1990; Shaikh, 2006). Así pues, la propiedad privada de los medios de producción determina las relaciones de clase, esto es, la relación entre capital y trabajo. Ésta a su vez se presenta conflictiva, pues los intereses de clase son antagónicos, en la medida en que en el capitalismo "los organizadores de la producción son en este caso capitalistas industriales, la expansión o contracción de la producción, vale decir, la distribución de las fuerzas productivas, depende de ellos" (Rubin, 1974:280). Luego toda empresa privada es autónoma y, por consiguiente, el propietario individual e independiente velará por sus propios intereses, pues estarán sujetos a la ganancia futura o, en otros términos, están gobernados por "el apetito insaciable de ganar" (Marx, 2006a:109). Así pues, la propiedad privada se erige como la institución principal que moldea el resto de instituciones en el capitalismo, en especial el Estado, pues éste "es aquella comunidad humana que, dentro de un determinado territorio (el territorio es elemento distintivo), reclama (con éxito) para sí el monopolio de la violencia física legitima" (Weber, 2001:83). 
En efecto, el Estado, como Leviatán, garantiza la propiedad privada de los medios de producción, pues concentra el monopolio de la violencia y la justicia, y con ello los intereses de una clase, la capitalista, son salvaguardados. En consecuencia, la propiedad privada determina las relaciones de clase; los productores desposeídos de sus medios de trabajo, es decir, los trabajadores, son ajenos a su producto, en tanto que el propietario dispone del producto de su empresa para que éste se realice como mercancía en el mercado. En palabras de Isaak Rubin; "todo productor de mercancía elabora mercancías, esto es, productos que no están destinados a su uso personal, sino al mercado, a la sociedad" (Rubin, 1974:55). De este modo, no se comprenden las relaciones de producción capitalistas sin el fetichismo de la mercancía; el intercambio de mercancías en el mercado capitalista conecta a todos los productores y propietarios individuales, redistribuyendo las fuerzas productivas.

Consiguientemente, el intercambio de mercancías se muestra como variable indispensable en el proceso de reproducción, luego la actividad laboral de un individuo podrá influir en la actividad laboral de otro; "las relaciones sociales que se establecen entre sus trabajos privados aparecen como lo que son; es decir, no como relaciones directamente sociales de las personas en sus trabajos, sino como relaciones materiales entre personas y relaciones sociales entre cosas" (Marx, 2006a:38). Por lo tanto, la circulación de mercancías construye y conforma las relaciones de producción, pues las mercancías adquieren las propiedades sociales del valor y el dinero (Marx, 2006a; Rubin, 1974). El dinero no es un mero símbolo, ni tampoco una mercancía cualquiera, sino el equivalente general que regula el intercambio de mercancías, pues "las relaciones sociales de producción no están sólo simbolizadas, sino que se realizan a través de las cosas" (Rubin, 1974:60). Estamos frente a otro rasgo distintivo del modo capitalista de producción, a saber; los productores son libres de vender la única propiedad de la que disponen, su fuerza de trabajo, pues están desposeídos, no solo de sus medios de producción, sino también de los medios de pago para adquirir los bienes que permitan su propia subsistencia. El trabajador desposeído entra en competición con el propietario de los medios de producción, en cuanto a que el primero está dispuesto a vender la única mercancía de la que dispone a cambio de un salario que cubra sus necesidades vitales y mejoré sus condiciones de vida, esto es, su capacidad de trabajo, mientras que el segundo busca una mercancía, la cual, al ser consumida le reporte valor, pues desea saciar su apetito de incrementar sus ganancias, y ésta será la fuerza de trabajo.

Trabajador y capitalista entrarán en conflicto; el conflicto capital-trabajo es la competencia entre el propietario y el productor, entre el capital y el trabajo, entre el salario y la ganancia. Las relaciones de producción determinan la distribución del ingreso, esto es, "tiene una estructura de clase determinada por la propia estructura del modo de producción y está gobernada a mediano plazo por los intereses de clase de los capitalistas" (Mandel, 1985:105). Efectivamente, nos referimos a la lucha de clases, la cual se expresa como la pugna distributiva por los aumentos de la productividad, pero ésta no es un producto exclusivo del capitalismo, pues ha estado presente en la historia de la humanidad, pero que adquiere en el modo capitalista de producción una determina forma; el conflicto capitaltrabajo.

En Marx, la lucha de clases no puede, en forma alguna, comprenderse sin el papel del Estado, pues éste "no es de ningún modo un poder impuesto desde fuera de la sociedad; tampoco es la realidad de la idea moral, ni la imagen y la realidad de la razón, como afirma Hegel" (Engels, 2010:242). El Estado, dice Vladimir Lenin, "es el producto y la manifestación del carácter irreconciliable de las contradicciones de clase" (Lenin, 1978:7). El Estado no es autónomo, ni tampoco cautivo, del mercado. El Estado moderno, o sea el 
Estado capitalista, es la superación del orden feudal, pues nace del contrato social, de "la idea de que los hombres son los autores de su sociedad mediante un pacto originario, que a veces se desdobla en un pacto de asociación (civil) y un pacto de dominación (política)" (Althusser, 1974:26). Negar la naturaleza capitalista del Estado, equivale a incurrir en el error cabal de la economía neoclásica; la despolitización de la economía. En vista de ello, nuestro estudio se configurará del siguiente modo: en el apartado segundo, analizaremos las categorías del valor, el trabajo y el plusvalor en Marx, su relación con la teoría de Ricardo, y la crítica neoclásica. En el tercer apartado, examinaremos las aportaciones de Schumpeter y Kalecki en la economía política. Por último, extraeremos algunas conclusiones.

\section{VALOR, TRABAJO ABSTRACTO Y PLUSVALOR: MARX, RICARDO Y LA CRÍTICA NEOCLÁSICA}

Antes de Marx, la economía política estaba gobernada por la idea infundada de que la ganancia nacía de la diferencia entre el precio de mercado y el valor o, dicho de otro modo, la venta de la mercancía por encima de su valor; la economía política postulaba que el determinante del precio de la mercancía es el salario y, en consecuencia, la elevación del coste del trabajo encarecería los precios y, por ende, era obligado reducir los salarios para incrementar el margen de las ganancias (Marx, 1978:210). David Ricardo, antes que Marx, señaló la confusión que dominaba a sus contemporáneos:

Cuando se requiere más oro, éste subirá, y los sombreros bajarán de precio, pues mayor cantidad de ellos y de las demás cosas será necesaria para adquirir la misma cantidad de oro. Pero en el caso supuesto antes, decir que las mercancías subirán porque suben los salarios es afirmar una contradicción indudable, pues nosotros decimos, en primer lugar, que el oro subirá en valor relativo a consecuencia del aumento de la demanda, y, en segundo lugar, que descenderá en valor relativo, porque subirán los precios: dos efectos que son absolutamente incompatibles (Ricardo, 1973:84).

Gran parte de los economistas contemporáneos de Ricardo se entregaron a la tarea de demostrar que la ganancia brotaba de un recargo sobre los precios de las mercancías o, en cualquier caso, de la venta de mercancías por un precio que excedía su valor (Marx, 1978; y 2006a). Nada más lejos de la realidad. La economía política no alcanzaba a descifrar la fuente de la ganancia. Solo Ricardo pareció acercarse a su origen; el economista inglés, al igual que su predecesor, Adam Smith, consideraba como la fuente del valor, el trabajo humano. Ricardo fue bastante claro a este respecto: "El valor de cambio de las cosas que poseen utilidad tiene dos orígenes: su escasez y la cantidad de trabajo requerida para obtenerlas" (Ricardo, 1973:20).

Efectivamente, cuando "hablamos, pues, de bienes, de su valor de cambio y de las leyes que rigen sus precios relativos, nos referimos exclusivamente a aquellos bienes cuya cantidad puede ser aumentada por efecto de la actividad humana" (Ricardo, 1973:20). De esta cita, se desprende que el determinante del valor de cambio y, por ende, el precio, es la cantidad de trabajo humano requerido, así como el tiempo necesario para la producción. Los precios, por tanto, están regulados por los costes de producción, y no sólo por las curvas de oferta y demanda, pues los precios de mercado, constantemente cambiantes, gravitan alrededor de otros precios más básicos, los precios naturales o, en términos de Marx, los precios de producción (Shaikh, 2009). Sin embargo, Ricardo quedó seducido por la teoría de los 
species-flow de David Hume (Shaikh, 2009), esto es, la teoría cuantitativa del dinero. El economista inglés entró en contradicción, a saber; mientras que acertaba en su afirmación sobre los costes de producción como reguladores de los precios, se mostró, al mismo tiempo, partidario del postulado de Hume, el cual establece que la cantidad de dinero en circulación determina el nivel general de precios (Ricardo, 1973). Marx rechazó aquel aserto por lo equivocado de su razonamiento:

La ilusión de que son, por el contrario, los precios de las mercancías los que dependen de la masa de los medios de circulación y ésta, a su vez, de la masa del material dinero existente dentro de un país, es una ilusión alimentada en sus primitivos mantenedores por la absurda hipótesis de que las mercancías se lanzan al proceso circulatorio sin precio y el dinero sin valor y que luego, allí, una parte alícuota de la masa formada por las mercancías se cambia por una parte alícuota de la montaña de metal (Marx, 2006a:82).

Es claro que el precio y, consecuentemente, el valor de cambio, no están determinados en exclusiva por las curvas de oferta y demanda, y aún menos por la cantidad de dinero, sino por la cantidad de trabajo que contiene una mercancía y los costes para su producción. En consecuencia, el equilibrio entre la oferta y la demanda no es resultado del azar, sino que está determinado por las condiciones técnicas de producción (Ricardo, 1973; Marx, 2006b, 2006c; Rubin, 1974). Queda preguntarse cuál es la fuente de la ganancia, cuál es su origen y de dónde brota. Ricardo había presentado a sus contemporáneos la clave para descifrar el enigma; la fuente de la ganancia se halla en el trabajo humano.

La crítica de Marx al postulado sobre que la ganancia brota de un sobrecargo en los precios, es contundente, como acertada: "Lo absurdo de esta idea se evidencia con generalizarla. Lo que uno ganase como vendedor, tendría que perderlo como comprador" (Marx, 1978:210). Marx profundiza más sobre esta cuestión en el primer volumen de $E l$ Capital:

Puede ocurrir que el poseedor de mercancías A sea tan astuto, que engañe a sus colegas $B$ o $C$ y que éstos, pese a toda su buena voluntad, no sean capaces de tomarse la revancha. A vende a $B$ vino por valor de 40 libras esterlinas y recibe a cambio trigo por valor de 50 libras. Mediante esta operación A habrá convertido su 40 libras en 50, sacando más dinero del que invirtió y transformando su mercancía en capital. Observamos la cosa más de cerca. Antes de realizarse esta operación, teníamos en manos de A vino por valor de 40 libras esterlinas, y en manos de B trigo por valor de 50 libras, o sea, un valor total de 90 libras esterlinas. Realizada la operación, el valor total sigue siendo el mismo: 90 libras. El valor circulante no ha aumentado ni un átomo: lo único que ha variado es su distribución entre $A$ y B. Lo que de un lado aparece como plusvalía, es del otro minusvalía; lo que de una parte representa un más, representa de la otra menos (Marx, 2006:117).

El filósofo de Tréveris lo deja claro; "nadie puede sacar de la circulación más valor del que metió en ella" (Marx, 2006:115). El recargo sobre los precios en forma alguna es la fuente de la ganancia. La producción de mercancías por medio de mercancía es una condición sine qua non para el capitalismo, por ello, debemos pasar de vender para comprar, M-D-M, a comprar para vender, D-M-D. No obstante, si se intercambian mercancías, o mercancías por dinero con un mismo valor de cambio, no se está creando más valor, ni generando ganancia alguna. Por tanto, para que el dinero se transforme en capital, y el capital 
en ganancia, debe cumplirse, D-M-D', donde ${ }^{D^{\prime}}=(D+\Delta D)$. En vista de ello, debe existir una mercancía, la cual, mientras es consumida, genere valor. La ley objetiva del valor, esto es, la teoría valor trabajo, nos conduce al origen de esta mercancía; Marx, al igual que Ricardo, reconoce como fuente del valor el trabajo humano, puesto que "lo que determina la magnitud de valor de un objeto no es más que la cantidad de trabajo socialmente necesario, o sea el tiempo de trabajo socialmente necesario para su producción" (Marx, 2006a:7). Asimismo, la cantidad de trabajo socialmente necesario tendrá como unidades de medida "las distintas fracciones de tiempo: horas, días, etc.” (Marx, 2006a:6), pues el tiempo de trabajo socialmente necesario "es aquel que se requiere para producir un valor de uso cualquiera, en las condiciones normales de producción y con el grado medios de destreza e intensidad de trabajo imperantes en la sociedad" (Rubin, 1974:225). Se comienza a vislumbrar cuál es la fuente de la ganancia.

$\mathrm{Su}$ origen debe estar en el trabajo humano. Por ello, Marx es más profundo en su análisis del trabajo humano, a saber; el trabajo humano encarnado en las mercancías es trabajo concreto y trabajo abstracto. El trabajo concreto es aquel que tiene un carácter técnico material, que en palabras de Marx, "representa capacidad productiva de trabajo útil, concreto" (Marx, 2006a:13). Es decir, "el trabajo útil rendirá una cantidad más o menos grande de productos según el ritmo con que aumente o disminuya su capacidad productiva" (Marx, 2006a:13). Por tanto, el trabajo concreto es aquel que se destina a la creación de los valores de uso, luego cuanto mayor sea la cantidad de valores de uso, mayor la riqueza material. Marx, sin embargo, señala el carácter diferente del valor de uso y el valor: "El mismo trabajo rinde, por tanto, durante el mismo tiempo, idéntica cantidad de valor, por mucho que cambie su capacidad productiva. En cambio, puede arrojar en el mismo tiempo cantidades distintas de valores de uso, mayores o menores según que su capacidad productiva aumente o disminuya" (Marx, 2006a:13). Riqueza y valor no son lo mismo.

Ricardo ya hubo de señalarlo: "el valor difiere esencialmente de la riqueza, pues aquél no depende de la abundancia, sino de la dificultad o facilidad de producción" (Ricardo, 1973: 231). Marx, al igual que Ricardo, señala la diferencia entre el valor y la riqueza, por ello, establece que todo "trabajo es, de una parte, gasto de fuerza humana de trabajo en el sentido fisiológico y, como tal, como trabajo humano igual o trabajo humano abstracto, forma el valor de la mercancía” (Marx, 2006a:13).

Mas, Rubin advierte de la interpretación literal de esta cita, pues "Marx nunca se cansó de repetir que el valor es un fenómeno social" (Rubin, 1974:189). En efecto, el trabajo abstracto no se puede reducir a trabajo fisiológico, pues presenta una carácter social e histórico, esto es: "Si no nos quedamos con las definiciones preliminares que dio Marx en las primeras páginas de su obras y nos dedicamos a rastrear el ulterior desarrollo de su pensamiento, hallaremos en la obra de Marx elementos suficientes para una teoría sociológica del trabajo abstracto" (Rubin, 1974:189). Si reducimos el valor analíticamente al trabajo abstracto, entendemos a éste en un sentido fisiológico. En cambio, Marx derivó dialécticamente el valor del trabajo abstracto, puesto que "el gasto de energía fisiológica como tal no es trabajo abstracto ni crea valor" (Rubin, 1974:190).

El trabajo abstracto se contrapone al trabajo concreto, pues incluye en su definición las formas sociales de la organización del trabajo humano. Así pues, el trabajo "es social si se lo examina como parte de la masa total de trabajo social homogéneo o, como dice Marx con frecuencia, si se lo ve en términos de su relación con el trabajo total de la sociedad" (Rubin, 1974:195). No cabe la menor duda de que en Marx, el trabajo abstracto es la fuente del valor y, en consecuencia, "el precio de una mercancía en el mercado coincide con su valor" (Marx, 
1978:209). Ahora bien, los precios de mercado oscilan a consecuencia de las fluctuaciones en la oferta y la demanda, pero en forma alguna determinan el valor de la mercancía, pues el precio de mercado puede presentarse una veces por encima, y otras por debajo, del precio natural, pero de un modo u otro, acaban igualándose. Marx reconoce que "la oferta y la demanda tienen que tender siempre a equilibrarse, aunque sólo lo hagan compensando una fluctuación con otra, un alza con una baja, y viceversa" (Marx, 1974:209). Por tanto, las mercancías tienden a venderse por su valor, esto es, por su precio natural o, si se prefiere, por su precio de producción.

El postulado que establece que la ganancia nace del recargo sobre los precios se hunde por su propio peso. El misterio parece llegar a su fin. Hemos dicho que el trabajo contenido en las mercancías es, por una parte, trabajo concreto y, por otra, trabajo abstracto. Hemos subrayado que el trabajo útil, concreto, crea valores de uso, riqueza, en tanto que el trabajo abstracto, por su carácter social e histórico, es la fuente del valor de la mercancía. Hemos advertido que en la esfera de circulación no se genera más valor que el ya existente. Ahora nos queda desvelar cuál es esa mercancía específica que cuando es consumida, genera valor. Recordemos que al referirnos a las relaciones de producción capitalistas, los productores se han visto despojados de sus medios de producción y, por ende, el trabajo es trabajo asalariado. Esto parece lógico, y carente de dificultad alguna en su compresión. Sin embargo, la economía política clásica no llegó a percatarse de lo siguiente: el trabajo no es una mercancía. Marx fue elocuente al respecto:

Después de analizar, en la medida en que podíamos hacerlo en un examen tan rápido, la naturaleza del valor, del valor de una mercancía cualquiera, hemos de encaminar nuestra atención al peculiar valor del trabajo. $Y$ aquí, nuevamente tengo que provocar vuestro asombro con otra aparente paradoja. Todos vosotros estáis convencidos de que lo que vendéis todos los días es vuestro trabajo; de que, por tanto, el trabajo tiene un precio, y de que, puesto que el precio de una mercancía no es más que la expresión en dinero de su valor, tiene que existir, sin duda, algo que sea el valor del trabajo. $Y$, sin embargo, no existe tal cosa como valor del trabajo, en el sentido corriente de la palabra (Marx, 1978:211).

Los cimientos de la economía política clásica se tambalean con estas palabras ya que lo que realmente vende un trabajador no es su trabajo, sino su capacidad de trabajo, su fuerza de trabajo.

De aquí brota la ganancia, de la fuerza de trabajo, puesto que "para obtener valor del consumo de una mercancía, nuestro poseedor de dinero tiene que ser afortunado, que dentro de la órbita de la circulación, en el mercado descubra una mercancía cuyo valor de uso posea la peregrina cualidad de ser fuente de valor, cuyo consumo efectivo fuese, pues, al propio tiempo, materialización de trabajo, y, por tanto, creación de valor" (Marx, 2006a:121). En efecto, esta mercancía específica es la fuerza de trabajo. Mas, Marx, anticipándose a sus críticos, subraya que el trabajador, al vender su fuerza de trabajo, cede temporalmente el derecho al propietario de los medios de producción de disponer de ella (Marx, 1978), porque es "necesario que el dueño de la fuerza de trabajo sólo la venda por cierto tiempo, pues si la vende en bloque y para siempre, lo que hace es venderse a sí mismo, convertirse de libre en esclavo, de poseedor de una mercancía en mercancía" (Marx, 2006a:121). Cuando nos referimos a la fuerza de trabajo como una mercancía, nos referimos a la capacidad de trabajo, a los servicios del trabajo, no al trabajador en su esencia. 
La crítica moral a este aspecto tan fundamental del enfoque de Marx, ha tratado de impugnar el análisis marxiano, alegando que la fuerza de trabajo es una mercancía espuria, puesto que los trabajadores no son mercancía alguna (Polanyi, 2007). Mas, la claridad del análisis de Marx sobre la naturaleza de la fuerza de trabajo como mercancía, no permite duda alguna al respecto; el mercado de fuerza de trabajo no es un mercado de trabajadores, puesto que si se vendiese la fuerza de trabajo sin límites de tiempo, entonces estaríamos hablando del restablecimiento de la esclavitud. Bajo ninguna circunstancia ocurre aquello, pues "algunas leyes continentales, -dice Marx-, fijan el máximo tiempo por el que una persona puede vender su fuerza de trabajo" (Marx, 1978:211). Por ello, Marx lanza la siguiente pregunta: “¿Qué es, pues, el valor de la fuerza de trabajo?” (Marx, 1978:213). A lo que enseguida responde: "Al igual que el de toda otra mercancía, este valor se determina por la cantidad de trabajo necesaria para su producción” (Marx, 1978:213). Ricardo conocía la respuesta, pero, paradójicamente, no alcanzó a descifrar la diferencia entre el trabajo y la fuerza de trabajo: "El precio natural del trabajo es aquel que es necesario, por término medio, para que los trabajadores subsistan y creen una familia en que reproduzcan sin aumento ni disminución" (Ricardo, 1973:75). En efecto, el valor de la fuerza de trabajo equivale al valor de las subsistencias que consienten la reproducción de la fuerza de trabajo, y el mantenimiento de las familias de los trabajadores. Hemos descubierto la clave para desentrañar la fuente de la ganancia.

El mercado de mercancías implica un intercambio de equivalentes, en la medida en que la "circulación es la suma de todas las relaciones de cambio que se establecen entre los poseedores de mercancías" (Marx, 2006a:119). Pero, como advertimos, el intercambio de mercancías con un mismo valor de cambio, no genera nuevos valores, ni tampoco ganancia. Por ello, la fuerza de trabajo se presenta como la mercancía específica, puesto que en la "transformación de valor del dinero llamado a convertirse en capital no puede operarse en este mismo dinero, pues el dinero, como medio de compra y medio de pago, no hace más que realizar el precio de la mercancía que compra o paga, manteniéndose inalterable en su forma genuina, como cristalización de una magnitud permanente" (Marx, 2006a:121). Llegados a este punto, qué es lo que hace especifico a la fuerza de trabajo; el valor de la fuerza de trabajo, como indicamos, equivale al precio de los bienes salario y, en consecuencia, en una jornada laboral de ocho horas, el trabajo necesario para reproducir el valor de los bienes de subsistencia será inferior a la jornada completa, pudiendo quedar reducido a cuatro horas de trabajo necesario.

En consecuencia, "cuando el capitalista "consume" fuerza de trabajo en el proceso de producción, el trabajador produce valor" (Mandel, 1985:49), pues el resto de la jornada laboral, o sea las cuatro horas restantes, se trata de trabajo excedentario que es apropiado por el capitalista en forma de plusproducto y plusvalor. El plusproducto y el plusvalor le corresponden al capitalista, puesto que el trabajador "como ha vendido su fuerza de trabajo al capitalista, todo el valor, o sea, todo el producto creado por él pertenece al capitalista, que es el dueño pro tempore de su fuerza de trabajo" (Marx, 1978:214). Por lo tanto, el valor de la fuerza de trabajo queda determinado por el tiempo de trabajo necesario para su producción, es decir, la reproducción de la fuerza de trabajo, pues el trabajador necesita "reponerse". En vista de ello, el "consumo de la fuerza de trabajo es, al mismo tiempo, el proceso de producción de la mercancía y de la plusvalía” (Marx, 2006a:128).

Mas una parte de la cantidad de trabajo corresponde al equivalente del valor de la fuerza de trabajo, esto es, el salario, en tanto que otra parte corresponde a un valor por el que no se pagó equivalente alguno; el trabajo excedente. Nos referimos, por tanto, al trabajo no retribuido, a la explotación de la fuerza de trabajo por parte del capital. Por consiguiente, 
"cuando el capitalista vende la mercancía por su valor, es decir, como cristalización de la cantidad de trabajo invertido en ella, tiene necesariamente que venderla con ganancia" (Marx, 1978:217). Consiguientemente, la ganancia es el plusvalor metamorfoseado en el proceso de realización de la mercancía, es decir, procede de la parte del valor de la mercancía materializado en el trabajo excedente. Asimismo, el plusvalor es la suma de la renta, el interés y la ganancia:

El monopolio del suelo permite al terrateniente embolsarse una parte de esta plusvalía bajo el nombre de renta del suelo, lo mismo si el suelo se utiliza para fines agrícolas que si se destina a construir edificios, ferrocarriles o a otro fin productivo cualquiera. Por otra parte, el hecho de que la posesión de los medios de trabajo permita al empresario capitalista producir una plusvalía o, lo que viene a ser lo mismo, apropiarse una determina cantidad de trabajo no retribuido, es precisamente lo que permite al propietario de los medios de trabajo, que los presta total o parcialmente al empresario capitalista, en una palabra, al capitalista que presta el dinero, reivindicar para sí mismo otra parte de esta plusvalía, bajo el nombre de interés, con lo que el empresario capitalista, como tal, sólo le queda la llamada ganancia industrial o comercial (Marx, 1978:217).

En la explotación de la fuerza de trabajo por parte del capital se origina la ganancia, pues el capital es una relación social entre personas que aparece como una relación entre cosas o bienes, entre personas y cosas (Mandel, 1985). Por ello, Marx diferencia el capital en sus formas variable y constante; el capital variable representa la parte del capital total dedicada a la inversión de fuerza de trabajo, esto es, trabajo vivo. En tanto que el capital constante es aquel que se dirige a la inversión de medios de producción, o sea, maquinaria y materias primas. La maquinaria representa el trabajo muerto, que no es generador de plusvalor, mientras que el trabajo vivo es la fuente de la ganancia; la reproducción ampliada de capital implica constantes revoluciones tecnológicas, que junto a la competencia real entre capitales, alienta a los capitalistas a incorporar máquinas para ahorrar tiempo de trabajo, pues se sustituye fuerza de trabajo por maquinaria, trabajo vivo por trabajo muerto (Marx, 2006b; Mandel, 1985).

De este modo, el capital variable corresponde a una parte más pequeña del total del capital. La caída de los costes de producción, a consecuencia del aumento de la productividad, se materializa en el descenso del valor de las mercancías. En efecto, el desarrollo de las fuerzas productivas entra en contradicción con las relaciones de producción.

Las decisiones de inversión de los capitalistas se ven socavadas, puesto que la rentabilidad esperada, esto es, la tasa de ganancia esperada, se muestra decreciente, materializándose en crisis de acumulación. Por ello, se ponen en movimiento todas las medidas para contrarrestar esta tendencia, a saber; intensificación del grado de explotación, reducción del coste de los elementos del capital constante, desvalorización la fuerza de trabajo, superpoblación relativa y búsqueda de nuevos espacios de valorización del capital (Marx, 2006c; Mandel, 1985; Grossman, 1979). Este análisis de Marx sobre la naturaleza contradictoria del modo de producción capitalista, fue soslayado por la economía neoclásica, la cual despolitizó todo el análisis económico. La crítica a Marx no tardó en llegar, a saber; los valores, a diferencia de los precios, no son algo observable, ni tampoco existe institución alguna que los determine, por ello se trata de un concepto metafísico, y como tal, no es aplicable a la realidad (Morishima, 1977; Robinson, 1942; King, 2009). 
El economista austríaco, Eugen Böhm-Bawerk, fue el primero quien creyó haber derruido el edificio teórico de la teoría objetiva del valor de Marx (Mandel, 1985; Rubin; 1974) y, en consecuencia, muchos han considerado la crítica de Böhm-Bawerk (Rubin, 1974), la refutación definitiva a la teoría de la explotación marxiana, pues los "argumentos de BöhmBawerk parecen a primera vista tan convincentes que podríamos decir osadamente que ninguna crítica posterior fue concebida sin repetirlo" (Rubin, 1974:113). El economista austriaco rechazó de plano la teoría objetiva del valor, prefiriendo desarrollar la teoría subjetiva, esto es, la escasez y la utilidad de un bien determinan su valor, pues para BöhmBawerk, "el sistema de Marx es un desarrollo lógico-deductivo, puramente lógico, de conceptos abstractos y su desarrollo inmanente, por el método de Hegel" (Rubin, 1974:143). Pero en eso se queda, porque se construye a partir de un erróneo punto de partida, a saber; que la fuente del valor es el trabajo humano. Sin embargo, la teoría subjetiva del valor ya había sido definida por Ricardo, pero el economista clásico la concretó para un cierto número de bienes, que por su rareza, sólo podían ser medidos por su escasez (Ricardo, 1973). No existe novedad alguna en la teoría de Böhm-Bawerk.

La crítica contra la teoría marxiana gravita alrededor de la omisión que hizo Marx sobre la relación entre el precio de mercado, el precio de producción y las curvas de oferta y demanda. Los críticos de Marx señalan que soslayó los efectos de la oferta y la demanda en la determinación de los precios, pero, como dice Fredy Perlman, "Marx no se preguntaba qué es lo que determina el precio comercial; se preguntaba cómo se regula la actividad laboral" (Perlman, 1974:33). La crítica a Marx resucitó la teoría de la utilidad de Jean Baptiste Say, y la teoría de los precios determinados por la oferta y la demanda de Augustin Cournot (Pelman, 1974). Para la economía neoclásica, el valor nace de la utilidad de la última unidad comprada y consumida, es decir, la "utilidad marginal", pues es el valor el que está determinado por la oferta y la demanda, y no al revés como señalaron Ricardo y Marx (Dobb, 1994; Rubin, 1974).

La "teoría valor trabajo" de Ricardo fue vaciada de contenido y sustituida por la teoría subjetiva del valor, mientras que la teoría de Marx fue desplazada, olvidada, porque, según sus críticos, no respondía a la divergencia existente entre el valor y el precio de producción (Mandel, 1985; Rubin, 1974; Shaikh, 2006). La economía neoclásica redujo las relaciones sociales, a las relaciones entre los productores y los consumidores, al homo economicus, al individualismo metodológico, porque, según Ludwig von Mises, la debilidad de la doctrina de Marx "consiste en que trata de clases y no de individuos" (Von Mises, 2003:151).

\section{RELACIONES DE PRODUCCIÓN Y CONFLICTO CAPITAL-TRABAJO DESPUÉS DE MARX: SCHUMPETER Y KALECKI}

\subsection{Schumpeter: competencia real y destrucción creativa}

La hegemonía de la economía neoclásica relegó el análisis de Marx a un segundo plano; el enfoque marxiano fue desarrollado fundamentalmente dentro de los marcos disciplinares de la filosofía y la sociología, en tanto que las ciencias económicas se entregaron a la conformidad del análisis diferencial, puramente matemático, y alejado de cualquier concepción filosófica más allá de la interpretación que se hizo del individualismo metodológico de Immanuel Kant (Von Mises, 2003). La economía neoclásica negó la posibilidad de que en el capitalismo pudieran sucederse episodios de crisis, pues el equilibrio general walrasiano garantizaba el ajuste automático a través de los precios, pero éste, olvidan 
los marginalistas, se alcanza bajo unas condiciones propias de una economía estacionaria (Myrdal, 1999).

No hubo, pues, una teoría de los ciclos económicos en la mayoría de los enfoques de economía neoclásica. Las excepciones fueron la escuela austríaca y los economistas suecos de la escuela escandinava; ambas tradiciones de la economía neoclásica se vieron fuertemente influenciadas por el análisis del ciclo monetario del economista Knut Wicksell (Teixeira, 1999), quien estableció la diferencia entre el interés de mercado y el interés natural, además de impugnar la neutralidad del dinero postulada por Hume y Ricardo (Myrdal, 1999). Fuera de la órbita de estas escuelas, quien planteó, y desarrollo, con más profundidad una teoría del ciclo conectada con las relaciones de producción, fue Joseph Alois Schumpeter; la influencia de Marx en el economista austriaco es palpable, pues partiendo del análisis de la tendencia de la tasa de ganancia y la competencia real entre capitales, hizo hincapié en las relaciones de clases, el papel del Estado y el parlamentarismo, en el funcionamiento del capitalismo (Schumpeter, 1952). Asimismo, enriqueció su cuerpo teórico con las aportaciones de Werner Sombart sobre la destrucción creativa, la teoría de las ondas largas del economista ruso Nikoali Dmitiyevich Kondatriev y el análisis sociológico de Max Weber (Schumpeter, 1952). Por esta razón, el enfoque de Schumpeter se apartó en gran medida de las escuelas marginalistas, rechazando de plano el individualismo metodológico.

Ahora bien, es oportuno señalar que el enfoque de Sombart sobre la destrucción creativa, tan presente en Schumpeter, tiene su origen en la obra de Marx, a saber; la contradicción entre el desarrollo de las fuerza de productivas y las relaciones de producción se materializa, como dijimos, en la caída de la tasa de ganancia y las crisis de acumulación, y, por ende, se ponen en movimiento los factores contrarrestantes de los que dispone el capital. En el proceso para revertir las crisis, las fuerzas productivas se tornan en fuerzas destructivas, esto es, se destruyen capitales, para, de este modo, reiniciar el proceso de acumulación de capital (Marx, 2010; Schumpeter, 1952). Esto es, la competencia real, se refiere a "la competencia que da lugar a una superioridad decisiva en el costo o en localidad y que ataca no ya a los márgenes de los beneficios y de la producción de las empresas existentes, sino a sus cimientos y su misma existencia" (Schumpeter, 1952:124). A partir de esta relación, el análisis schumpeteriano señala la importancia de las transformaciones tecnológicas y el papel protagónico de los empresarios emprendedores $o$, en otros términos, empresarios schumpeterianos, en el desarrollo del modo capitalista de producción.

En efecto, Schumpeter comparte con el enfoque marxiano el análisis endógeno y orgánico de las transformaciones económicas, alejándose de la visión puramente exógena y estática que domina el pensamiento marginalista, pues el "capitalismo es, por naturaleza, una forma o método de transformación económica, y no solamente no es jamás estacionario, sino que no puede serlo nunca" (Schumpeter, 1952:121). El rico análisis de Schumpeter en cuanto a la relación entre la competencia real y los ciclos económicos no tuvo la relevancia que hubiese merecido; un gran número de economistas marxistas del siglo $\mathrm{XX}$, consideraban que el capitalismo había entrado en una fase dominada por los grandes monopolios y, en consecuencia, la teoría valor trabajo de Marx no operaba bajo este contexto (Sweezy y Baran, 1974; Boundi, 2013). Al calor de la teoría de la competencia monopolista, surgió la figura de Michal Kalecki, quien rescatando a Marx y Rosa Luxemburgo del olvido (King, 2009), anticipó los principios de la demanda efectiva de John Maynard Keynes a través del análisis marxiano de la tendencia de la tasa de ganancia y los esquemas de reproducción del segundo libro de El Capital (Robinson, 1970). 


\subsection{Kalecki: tasa de ganancia, conflicto capital-trabajo y ciclo político}

El largo deambular de la economía a consecuencia de la incapacidad de la teoría marginalista por comprender la naturaleza dinámica del modo capitalista de producción, ofuscó a un gran número de economistas, en especial, a John Maynard Keynes, quien pareció decidido en tirar el edificio teórico de la economía neoclásica; el economista de Cambridge subraya que la economía neoclásica descansa sobre tres postulados, a saber; primero, el salario real se iguala a la desutilidad marginal de la ocupación existente; segundo, no existe la desocupación involuntaria; tercero, la oferta crea su propia demanda, esto es, se cumple la Ley de Say (Keynes, 2012).

Estas tres condiciones fueron impugnadas por Keynes en su Teoría general de la ocupación, el dinero y el interés, pues los principios de la demanda efectiva gravitan alrededor de la premisa de que "cuando aumenta la ocupación aumenta también el ingreso agregado real de la comunidad; la psicología de ésta es tal que cuando el ingreso real agregado aumenta, el consumo agregado crece pero no tanto como el ingreso" (Keynes, 2012:57). Por lo tanto, dada una cantidad de ocupación, es obligado que exista un determinado volumen de inversión que absorba el excedente de la producción total en función a las decisiones de consumo cuando la ocupación alcance tal nivel (Keynes, 2012). Este razonamiento basado en los principios de la demanda efectiva había sido anticipado por el economista polaco, Kalecki; a través del análisis de las relaciones de producción de Marx, Kalecki construye su modelo macroeconómico dividido en dos clases, trabajadores y capitalistas.

Al igual que Marx, el economista polaco establece que los trabajadores dedican todos sus ingresos a la compra de bienes que garanticen su subsistencia y la de sus familias, luego no tienen la capacidad para ahorrar parte de sus rentas (Kalecki, 1970, 1995). En tanto que los ingresos de los capitalistas, esto es, sus ganancias, dependen del consumo y la inversión que realicen, es decir, "sus decisiones sobre inversión y consumo determinan las ganancias, y no a la inversa" (Kalecki, 1995:47). De igual modo, pueden ahorrar parte de sus ingresos, pues la propensión a consumir de los capitalistas es menor que la unidad. Grosso modo, el ahorro agregado corresponde a los capitalistas, luego, bajo la definición de Joan Robinson, "los trabajadores gastan todo lo que ganan y los capitalistas ganan lo que gastan” (King, 2009).

Bajo estos supuestos, Kalecki, al igual que Marx, se entregó a la tarea de analizar la contradicción entre el desarrollo de las fuerzas productivas y las relaciones de producción reflejada en la caída de la tasa de ganancia; el análisis kaleckiano, establece que las ganancias totales están sujetas a los ritmos de la inversión, asimismo, estos ritmos son constantes, ergo, las ganancias totales también lo serán (Kalecki, 1970, 1995; Robinson, 1944). No obstante, al igual que Marx, el economista polaco establece que el acervo de capital fijo es creciente y, en consecuencia, la tendencia de la tasa de ganancia se mostrará decreciente. En vista de ello, las ganancias totales están gobernadas por la demanda efectiva, es decir, cuanto mayor sea la participación de los salarios en el total del producto, mayor el nivel de producto agregado (Keynes, 2012; Kalecki, 1970).

Ahora bien, la diferencia fundamental con el análisis marxiano, es la siguiente: Kalecki postula que la competencia capitalista está gobernada por los monopolios, esto es, prevalece la competencia oligopolística o imperfecta, luego la teoría valor trabajo en forma alguna opera, en la medida en que el trabajo no es libre y los grandes monopolios fijan los precios por encima de los costes marginales. En efecto, en el enfoque kaleckiano, los precios de mercado se alejan de los precios de producción, es decir, las mercancías no tienden a venderse por su valor como afirmaban los clásicos y Marx. El dominio de los grandes monopolios implica que el proceso de igualación de tasas de ganancia entre sectores no 
llegue a alcanzarse y, en consecuencia, los precios de mercado no tiendan a igualarse con el valor de las mercancías, pues, vale decir, la ley del valor no opera en estas condiciones.

De este modo, el conflicto capital-trabajo en Kalecki queda recogido en la formación de los precios; el economista polaco postula que la formación de precios está determinada por el grado de monopolio, es decir, las empresas tienen la capacidad de fijar un mark up, o margen sobre los costes, que será mayor cuanto mayor sea el grado de concentración de los sectores o ramas de la industria. En consecuencia, cuanto mayor sea el grado de monopolio, mayor la diferencia entre el precio y el coste marginal y, por consiguiente, las ganancias serán más elevadas. En efecto, la participación de los beneficios en el ingreso total crece conforme a cómo lo haga el grado de monopolio y, consecuentemente, la participación de los salarios decrece. Así pues, el economista polaco centra su análisis en el conflicto capital-trabajo, en cuanto a que éste es la materialización de la pugna distributiva por los aumentos de la productividad. Para ello, inspirado en la ecuación de la formación de precios de monopolio del economista neoclásico Abba Lerner (King, 2009), Kalecki expresa la formación de precios bajo la influencia del grado de monopolio, con el objeto de dilucidar la relación conflictiva entre las empresas y los sindicatos, y, por consiguiente, los problemas de distribución derivados del proceso concentración de capital de la industria (Kalecki, 1995:1120):

$$
P=\left(\frac{m}{1-n}\right) u ; \text { donde }\left(\frac{m}{1-n}\right)=\frac{B}{Y}
$$

En la expresión de Kalecki, $m$ y $n$, representan la política de precios de las empresas, $u$, los costes unitarios del trabajo y los bienes de producción, en tanto que $\left(\frac{m}{1-n}\right)$ expresa el grado de monopolio, el cual se iguala a la participación de los beneficios en el total del ingreso, $\frac{}{Y}$. A partir de esta expresión, Kalecki postula que la organización sindical tendrá la capacidad de reducir el grado de monopolio, pues la elevación de los precios moviliza a los trabajadores organizados en sindicatos a exigir incrementos salariales por encima de la inflación. En consecuencia, las empresas ante las exigencias de los sindicatos, decidirán reducir $m$ y $n$, esto es, el nivel de precios habrá descendido y, con ello, el grado de monopolio, pues "no se puede sostener una proporción elevada de ganancias a salarios sin crear una tendencia al alza de los costes" (Kalecki, 1995:19). Por lo tanto, la fuerte posición de los sindicatos obliga a las empresas a aceptar márgenes de utilidad más bajos.

Esto, a su vez, supone que las variaciones en el grado de monopolio "no sólo tienen importancia decisiva en la distribución del ingreso entre trabajadores y capitalistas, sino en ciertos casos también en la distribución del ingreso entre la propia clase capitalista" (Kalecki, 1995:19). Efectivamente, como indicamos, la presencia de grandes empresas monopolísticas, supone que los sectores con mayor concentración de capital gozan de mayores márgenes de beneficio y, en consecuencia, mayores tasas de ganancia, luego los grandes monopolios absorben una mayor porción de los ingresos agregados o, dicho de otra forma, se redistribuye ingreso de las pequeñas empresas a las empresas de mayor tamaño (Kalecki, 1995). Asimismo, Kalecki entiende que la competencia imperfecta implica que no se alcance la plena utilización de la capacidad instalada en la industria, esto es, una gran parte del capital instalado se mantiene ociosa (Kalecki, 1970). El capital ocioso supone el desempleo de la fuerza de trabajo, pues la industria no expande su producción hasta vaciar el mercado. La razón por la que los capitalistas no expanden su producción se encuentra, de nuevo, en el grado de monopolio, esto es, los monopolios no incrementan su producción más allá de un cierto nivel "porque el consecuente descenso del precio del bien producido podría provocar 
pérdidas en vez de ganancias" (Kalecki, 1970:100). Solo la movilización de los sindicatos podría revertir esta situación, puesto que tienen la capacidad de influir en el grado de monopolio.

Sin embargo, Kalecki advierte lo siguiente: por sí sola, la lucha sindical por los salarios no tiene la capacidad de transformar radicalmente la distribución de la renta en el modo de producción capitalista (King, 2009). Es necesario, pues, elevar los impuestos al capital, pero esto, en un régimen capitalista, es utópico, porque el Estado, como Leviatán, garantiza los intereses de la clase propietaria de los medios de producción. Kalecki comprendía perfectamente aquello, legándonos su teoría de los ciclos políticos (Kalecki, 2011): en los periodos de auge, dominados por el pleno empleo y las políticas de gasto público, la capacidad de negociación de los trabajadores se hace más fuerte, lo que da pie a la reacción del capital para revertir esta situación y, en consecuencia, el Estado reduce el gasto público, pues "los capitalistas de la industria se oponen a un estado de pleno empleo prolongado porque socava la disciplina de los trabajadores" (Bhaduri,1990:287).

Esto conecta con la teoría marxiana de las crisis por compresión de la ganancia (Bhaduri, 1990), a saber; un mayor poder de negociación de los sindicatos comprime las ganancias, en la medida en que un alto nivel de empleo eleva los salarios por encima de la variación de la productividad del trabajo. Por consiguiente, un periodo largo de pleno empleo reduce las ganancias y el ahorro de los capitalistas, lo que socava la inversión privada y, por ende, la economía entra en recesión. Por tal razón, Kalecki se mostró escéptico ante la posibilidad de alcanzar el pleno empleo dentro de los límites del capitalismo, pues, para ello, "el camino más racional, y esto sucedería en un sistema socialista, consistiría en aumentar la inversión, lo que aceleraría el desarrollo de la economía" (Kalecki, 1980:23). No obstante, subraya el economista polaco, "bajo el capitalismo, esto no sucede necesariamente. En realidad, actualmente, el excedente económico disponible se utiliza en gran parte en la producción de armamentos" (Kalecki, 1980:23-24).

\section{CONCLUSIONES}

La teoría económica siempre ha mostrado su afinidad con otras disciplinas de las ciencias sociales, en especial la filosofía, la sociología y la política. Desde los clásicos, hasta Marx, la economía era irreconocible sin el estudio de la política y el análisis de las relaciones de clase. La despolitización de la economía por parte de las escuelas marginalistas y utilitaristas que emergieron a partir de 1870, condujo a la desconexión con la realidad social, pues el individualismo metodológico implicaba el individualismo político $\mathrm{y}$, por ende, la racionalidad del sujeto, en avenencia con el mercado, era todo lo que necesitaba conocer la economía.

Sin embargo, se infravaloró el legado de Marx, pues se le enterró antes de comprenderlo: las crisis económicas no parecían ser un fenómeno aislado casual, mas aquello no pareció importar a la economía neoclásica. Las subsiguientes generaciones de economistas no compartieron esa despreocupación; las relaciones de producción y el conflicto capitaltrabajo, tal como fueron dilucidados por Marx, no habían perdido su fuerza, pues son parte esencial para la comprensión del capitalismo. Por ello, el análisis dialéctico de Marx mantiene su vigencia, ya que, al igual que Schumpeter y Kalecki, debemos comprender el papel de las instituciones modernas, las relaciones sociales y, en definitiva, la naturaleza de la producción capitalista. Por tanto, en modo alguno podemos desconectar estos aspectos del análisis de la economía política, más aún cuando la actualidad económica merece una visión 
más amplia para comprender la realidad a la que nos enfrentamos, lo cual, vale decir, no es algo casual, sino derivado de las contradicciones inherentes de este sistema.

\section{BIBLIOGRAFÍA}

ALTHUSSER, L. (1974). Montesquieu. La política y la historia. Barcelona: Ariel.

BARAN, P. y SWEEZY, P. (1974). El capital monopolista. Ensayo sobre el orden económico y social norteamericano. México D.F.: Siglo XXI.

BHADURI, A. (1990). Macroeconomía. La dinámica de la producción de mercancías. México D.F: FCE.

BOUNDI, F. (2013). "Estructuralismo latinoamericano y neomarxistas: el origen del proceso de subdesarrollo de la periferia", en Apuntes del CENES, 55: 9-31.

DOBB, M. (1994). Introducción a la economía. México D.F: FCE.

ENGELS, F. (2010). El origen de la familia, la propiedad privada y el Estado. Madrid: Pensamiento Crítico.

GROSSMANN, H. (1979). La ley de la acumulación y del derrumbe del sistema capitalista. Una teoría de la crisis. México D.F: Siglo XXI.

GUERRERO, D. (2011). Sismondi, precursor de Marx. Madrid: Maia.

KALECKI, M. (1970). Estudios sobre la teoría de los ciclos económicos. Barcelona: Ariel.

KALECKI, M. (1980). Ensayo sobre las economías en vías de desarrollo. Barcelona: Editorial Crítica.

KALECKI, M. (1995). Teoría de la dinámica económica. Ensayo sobre los movimientos cíclicos y a largo plazo de la economía capitalista. México D.F: FCE.

KALECKI, M. (2011). “Aspectos políticos del pleno empleo”, en Revista de Economía Crítica, 12: 214-222.

KEYNES, J. M. (2012). Teoría general de la ocupación, el interés y el dinero. México D.F: FCE.

KING, J. E. (2009). Una historia de la economía poskeynesiana desde 1936. Madrid: AKAL.

LENIN, V. I. (1976). El Estado y la revolución. Madrid: Endymion.

MANDEL, E. (1985). El Capital. Cien años de controversias en torno a la obra de Karl Marx. México D.F: Siglo XXI.

MARX, K. (1978): “Precios, salarios y beneficios”. En K. Marx y F. Engels. Obras Escogidas. Moscú: Progreso, pp. 186-232.

MARX, K. (2006a). El Capital. Crítica de la economía política. Vol. I. México D.F: FCE.

MARX, K. (2006b). El Capital. Crítica de la economía política. Vol. II. México D.F: FCE.

MARX, K. (2006c). El Capital. Crítica de la economía política. Vol. III. México D.F: FCE.

MARX, K. (2010). La crisis del capitalismo. Madrid: Pensamiento Crítico.

MORISHIMA, M. (1977). La teoría económica de Marx. Una Teoría dual del valor y el crecimiento. Madrid: Tecnos.

MYRDAL, G. (1999). Equilibrio monetario. Madrid: Pirámide.

PERLMAN, F. (1974). "El fetichismo de la mercancía". En I. I. Rubin. Ensayos sobre la teoría marxista del valor. Córdoba: Cuadernos de Pasado y Presente, pp. 9-43.

POLANYI, K. (2007). La gran transformación. Los orígenes políticos y económicos de nuestro tiempo. México D.F: FCE.

RICARDO, D. (1973). Principios de economía política y tributación. Madrid: Hora H.

ROBINSON, J. (1944). Ensayos sobre la economía marxista. México D.F: FCE.

ROBINSON, J. (1970). "Introducción". En M. Kalecki. Estudios sobre la teoría de los ciclos económicos. Barcelona: Ariel, pp. 5-17.

RUBIN, I. I. (1974). Ensayos sobre la teoría marxista del valor. Córdoba: Cuadernos de Pasado y Presente.

SCHUMPETER, J. A. (1952). Capitalismo, socialismo y democracia. México D.F: Aguilar.

SHAIKH, A. (2006). Valor, acumulación y crisis. Buenos Aires: Razón y Revolución.

SHAIKH, A. (2009). Teorías del comercio internacional. Madrid: Maia. 
TEIXEIRA, J. F. (1999). “Estudio preliminar”. En G. Myrdal. Equilibrio monetario. Madrid: Pirámide, pp. 11-44.

VON MISES, L. (2003). Teoría e historia. Una interpretación de la evolución social y económica. Madrid: Unión Editorial.

WEBER, M. (2002). El político y el científico. Barcelona: Alianza.

\section{Breve currículo:}

\section{Fahd Boundi}

Licenciado en Ciencias Económicas por la Universidad Complutense de Madrid y postgrado en Economía Internacional y Desarrollo de la Universidad Complutense de Madrid. Colaborador como analista económico de Periodistas-es.org y economista del departamento de Estudios y Proyectos de la Fundación $1^{\circ}$ de mayo. Líneas de investigación: relación entre la distribución del ingreso y la tasa de ganancia, efectos de la internacionalización en la economía mundial y el papel del Estado y las instituciones capitalistas en el proceso de acumulación de capital. 